\title{
Association of the germline TP53 R337H mutation with breast cancer in southern Brazil
}

\author{
Juliana G Assumpção ${ }^{1}$, Ana Luíza Seidinger ${ }^{1}$, Maria José Mastellato', Raul C Ribeiro ${ }^{2,3}$, Gerard P Zambetti ${ }^{4}$, \\ Ramapriya Ganti ${ }^{5}$, Kumar Srivastava ${ }^{6}$, Sheila Shurtleff ${ }^{5}$, Deqing Pei ${ }^{6}$, Luiz Carlos Zeferino ${ }^{7}$, Rozany M Dufloth ${ }^{8}$, \\ Silvia Regina Brandalise ${ }^{1}$ and José Andres Yunes ${ }^{1 *}$
}

\section{Correction}

Of the 123 patients included in our work [1], 44 were selected according to the following familial risk history criteria: early onset (less than 35 years of age); bilateral carcinoma; more than three cases of breast cancer and more than one case of ovarian cancer in the family; more than two first degree relatives involved; and male breast cancer. We regret that in the methods section of our manuscript [1], it was erroneously stated both that the number of patients with familial history was 45 and that the criteria used for their selection was: "had either more than three cases of breast cancer and more than one case of ovarian cancer in the family; or had more than two first-degree relatives with breast cancer; or had one case of male breast cancer" (only two out of these 44 patients would have fulfilled these criteria).

Fortunately, the information regarding the familial history of our breast cancer patients was added for descriptive reasons and was not a part of any results, statistical analysis or conclusions.

\section{Author details \\ ${ }^{1}$ Centro Infantil Boldrini, Campinas, Brazil. ${ }^{2}$ Department of Oncology, St. Jude Children's Research Hospital, Memphis, USA. International Outreach Program, St. Jude Children's Research Hospital, Memphis, USA. ${ }^{4}$ Department of Biochemistry, St. Jude Children's Research Hospital, Memphis, USA. ${ }^{5}$ Department of Pathology, St. Jude Children's Research Hospital, Memphis, USA. 'Department of Biostatistics, St. Jude Children's Research Hospital, Memphis, USA. ${ }^{7}$ Universidade Estadual de Campinas, Campinas, Brazil. ${ }^{8}$ Universidade Federal de Santa Catarina, Florianópolis, Brazil.}

Received: 13 April 2011 Accepted: 26 April 2011 Published: 26 April 2011

\section{Reference}

1. Assumpção JG, Seidinger AL, Mastellaro MJ, Ribeiro RC, Zambetti GP, Ganti R, Srivastava K, Shurtleff S, Pei D, Zeferino LC, Dufloth RM, Brandalise SR, Yunes JA: Association of the germline TP53 R337H mutation with breast cancer in southern Brazil. BMC Cancer 2008, 8:357.

Pre-publication history

The pre-publication history for this paper can be accessed here: http://www.biomedcentral.com/1471-2407/11/152/prepub

doi:10.1186/1471-2407-11-152

Cite this article as: Assumpção et al:: Association of the germline TP53 R337H mutation with breast cancer in southern Brazil. BMC Cancer 2011 11:152.

* Correspondence: andres@boldrini.org.br

${ }^{1}$ Centro Infantil Boldrini, Campinas, Brazil

Full list of author information is available at the end of the article

Submit your next manuscript to BioMed Central and take full advantage of:

- Convenient online submission

- Thorough peer review

- No space constraints or color figure charges

- Immediate publication on acceptance

- Inclusion in PubMed, CAS, Scopus and Google Scholar

- Research which is freely available for redistribution
() Biomed Central 